Note

\title{
Structural Determination of the Subsidiary Colors in Food Blue No. 1 (Brilliant Blue FCF) Aluminum Lake Detected by Paper Chromatography
}

\author{
(Received November 1, 2000)
}

\author{
Sumiko Tsuji*1, ${ }^{\dagger}$, Yoshiaki Amakura*1, Yukiko Umino*1, Masatoshi Nishi*2, \\ Tsutomu NAKANISHI*2 and Yasuhide TONOGAI*1 \\ (*1 Osaka Branch, National Institute of Health Sciences (NIHS): 1-1-43, Hoenzaka, Chuo-ku, Osaka \\ 540-0006, Japan; ${ }^{* 2}$ Faculty of Pharmaceutical Sciences, Setsunan University: 45-1, \\ Nagaotoge-cho, Hirakata, Osaka $573-0101$, Japan; ${ }^{\dagger}$ Corresponding author)
}

\begin{abstract}
One of eight Food Blue No. 1 aluminum lakes (B-1Als) used in the official inspection of coal-tar colors in fiscal year 1999 had a violet sub-spot during paper chromatography and was rejected. To clarify the orgin of the sub-spot, the violet subsidiary color (Sub-V) was isolated from the sample. On the basis of NMR and MS analyses and ion chromatography, the structure of the subsidiary color was elucidated to be 2-[[4-[N-ethyl- $N$-(3-sulfophenylmethyl)amino]phenyl][4-hydroxyphenyl]methylio]benzenesulfonic acid. The relative content of Sub-V to that of $m, m-\mathrm{B}-1$ in the rejected sample was determined to be $39.5 \%$ by HPLC. The relative contents in other submitted samples of $\mathrm{B}-1 \mathrm{Al}$ were in the range of $1.1-3.6 \%$.
\end{abstract}

Key words: Food Blue No. 1 aluminum lake; brilliant blue FCF aluminum lake; paper chromatography; subsidiary color; MS; NMR; polyamide; HPLC

\section{Introduction}

In Japan, twelve synthetic food colors and eight aluminum lakes are permitted for use in foods. They can be sold after passing the official inspection tests.

Recently, from the viewpoint of international harmonization, several studies have been performed to identify and quantify the subsidiary colors in Food Red No. $40^{1-4)}$, Food Red No. $2^{3-7)}$, Food Red No. $102^{31-9)}$, Food Red No. 10410), Food Yellow No. 53),4), 6), 8),11)-13), Food Blue No. 144-16), and Food Green No. $3^{17)}$ in Japan. Japan's Specifications and Standards for Food Additives, 7th Edition (JSFA-VII) specified the subsidiary colors in Food Red No. 40 and Food Yellow No. $5^{18)}$.

Food Blue No. 1 (B-1; CI No. 42090, brilliant blue FCF, FD \& C Blue No. 1) is classified as a triphenylmethane color prepared by the condensation of 1 mole of $o$-sulfobenzaldehyde (OSBA) and 2 moles of 3- $N$-ethyl$N$-benzylaniline sulfonic acid ( $m$-EBASA), and is called disodium salt of 2-[bis[4-[ $N$-ethyl- $N$-(3-sulfophenylmethyl)amino]phenyl]methylio]benzenesulfonic acid [OSBA-( $m$-EBASA)( $m$-EBASA); $m, m$-B-1]. Commercial B-1 product is a mixture of the isomers formed from $o$-, $m$-, and $p$-EBASA. Stein ${ }^{19)}$ and Kamikura ${ }^{14)}$ identified two subsidiary colors in commercial B-1 by comparison of the TLC or HPLC data with those of synthetic compounds; one was OSBA-(ethylbenzylaniline: $\mathrm{EBA})(m$ EBASA) [Sub-F] formed by the loss of one sulfonato group from B-1 and the other was OSBA-( $N$-ethylaniline: EA) $(m$-EBASA) $[$ Sub-E] formed by the loss of one sulfonatobenzyl group. Matsufuji et al. reported that recent commercial B-1 products contained five subsidiary colors, OSBA- $(m$-EBASA)( $p$-EBASA) $[m, p$-B- 1 ; Sub-C], OSBA- $(o-$ EBASA) $(m-\mathrm{EBASA})[o, m-\mathrm{B}-1 ;$ Sub-D $]$, Sub-E and two unidentified subsidiary colors (Sub-A and $\mathrm{B}$ ), other than $m, m$-B-1, which was the main compound ${ }^{15)}$. Furthermore, Kusaka et al. also identified a magenta subsidiary, OBSA-(4-oxo-2,5-cyclohexadienylidene: OCD)( $m$-EBASA) [Sub-M] in commercial B-1 products ${ }^{16)}$. The structures are shown in Fig. 1.

Food Blue No. 1 aluminum lake (B-1 Al) is prepared as a complex of B-1 and aluminum salt under alkaline conditions $^{18)}$. In fiscal year 1999, eight samples of B-1Al were submitted for official inspection. Because one of them had a violet sub-spot in addition to the main spot during paper chromatography (PC), it was rejected ${ }^{20)}$. Analytical HPLC of the rejected sample was performed under the conditions specified by Matsufuji et $a l^{15}$. The retention time $(R t)$ of the violet subsidiary color detected in it was similar to that of the Sub-M reported by Kusaka et $a l^{16)}$. Since we could not obtain authentic Sub-M, we isolated the violet subsidiary color (Sub-V) by column chromatography to identify its chemical structure by MS and NMR. We also surveyed its content in the samples of B-1Als submitted for official inspection in fiscal year 1999 . 


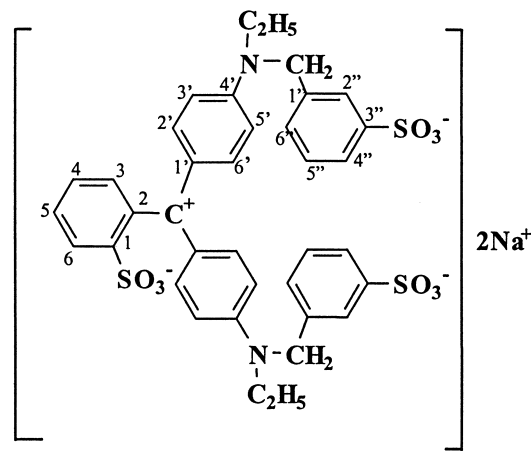

$m, m-\mathbf{B}-1$

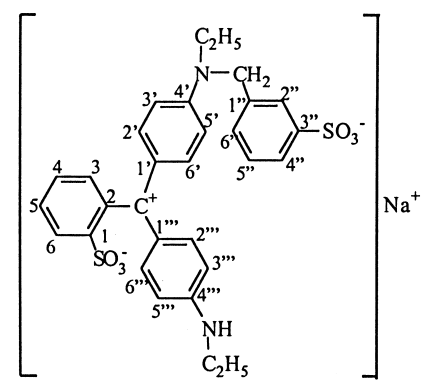

Sub-E: OSBA-(EA) $(m-\mathbf{E B A S A})$

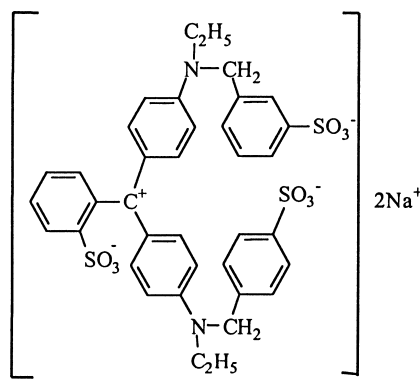

Sub-C: $m, p-\mathbf{B}-\mathbf{1}$

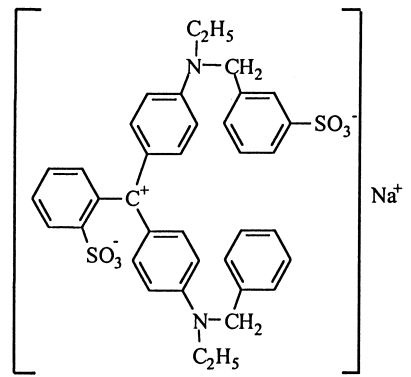

Sub-F: OSBA-(EBA)( $m$-EBASA)

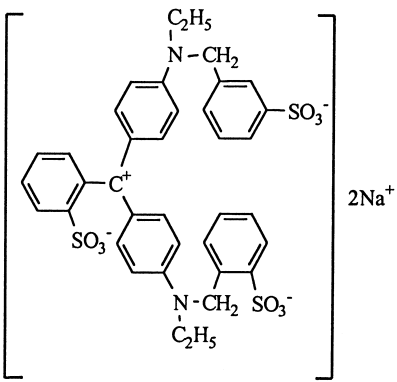

Sub-D: $o, m-\mathbf{B}-1$

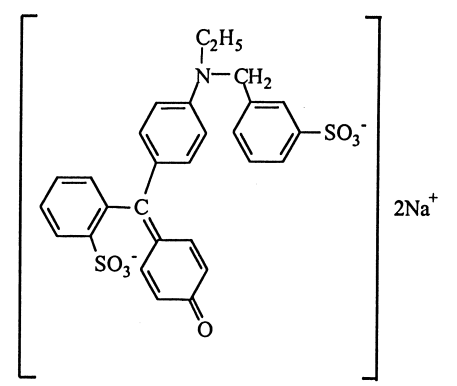

Sub-M: OSBA-(OCD)( $m$-EBASA)

Fig. 1. Chemical structures of the main component ( $m, m$-B-1) and known subsidiary colors in commercial B-1 $m, m$-B-1 [OSBA-( $m$-EBASA)( $m$-EBASA), the disodium salt of 2 -[bis[4- $N$-ethyl- $N$-(3-sulfophenylmethyl)amino]phenyl]methylio]benzenesulfonic acid; Sub-C: $m, p$-B-1 [OSAB-( $m$-EBASA) ( $p$-EBASA)], the disodium salt of 2-[[4- $N$-ethyl- $N$-(3sulfophenylmethyl) amino] phenyl][4- $N$-ethyl- $N$-(4 -sulfophenylmethyl) amino] phenyl] methylio] benzenesulfonic acid; Sub-D: $o, m$-B-1 [OSBA-(o-EBASA) $(m$-EBASA)], the disodium salt of 2-[[4- $N$-ethyl- $N$-2(sulfophenylmethyl)amino]phenyl][4- $N$-ethyl- $N$-(4-sulfophenylmethyl)amino]phenyl]methylio]benzenesulfonic acid; Sub-E [OSBA-(EA) ( $m$ EBASA)], the monosodium salt of 2-[[4- $N$-ethylamino)phenyl][4- $N$-ethyl- $N$-(3-sulfophenylmethyl)amino]phenyl]methylio]benzenesulfonic acid; Sub-F [OSBA-(EBA) $(m$-EBASA)], the monosodium salt of 2-[4-( $N$-ethyl- $N$-benzylamino)phenyl][4-[N-ethyl- $N$-(3-sulfophenylmethyl)amino]phenyl]methylio]benzenesulfonic acid; Sub-M [OSBA-(OCD) $(m-$ EBASA)], the disodium salt of 2-[[4- $N$-ethyl- $N$-(2-sulfophenylmethyl)amino]phenyl][4-oxo-2,5-cyclohexadienylidene]methyl]benzenesulfonic acid.

\section{Materials and Methods}

\section{Samples and reagents}

Eight official Japanese B-1Al samples submitted for official inspection in fiscal year 1999 were used. The brilliant blue FCF reference standard was a standard product distributed by NIHS and was used as $m, m-\mathrm{B}-1$. Polyamide C-200 for column chromatography was purchased from Wako Pure Chemical Industries, Ltd. (Osaka, Japan). Water was obtained from a Milli-Q SP. TOC. Reagent Water System (Millipore Co., Massachusetts, USA), and all other chemicals were of reagent or HPLC grade.

\section{Instruments}

Analytical HPLC was performed with a JASCO 880 system equipped with a photodiode array detector MD 1515 (JASCO Co., Ltd., Tokyo, Japan). Ion chromatography (IC) was done with an ion chromatograph DX-320 (Dionex Co., CA, U.S.A.). Electrospray ionization (ESI)MS was recorded on a Shimadzu QP-8000 mass spectrometer (Shimadzu Co., Kyoto, Japan) with 0.04\% ammonium carbonate as the solvent. Fast-atom bombardment (FAB)-MS was recorded on a JEOL DX-300 mass spectrometer (JEOL Co., Ltd., Tokyo, Japan) with glycerin as the matrix agent. ${ }^{1} \mathrm{H}-\mathrm{NMR}$ and ${ }^{13} \mathrm{C}-\mathrm{NMR}$ spectra were recorded on a Brucker OMEGA600 (Bruker Co., Ltd., Germany) instrument $\left(600 \mathrm{MHz}\right.$ for ${ }^{1} \mathrm{H}$, and 150 $\mathrm{MHz}$ for ${ }^{13} \mathrm{C}$ ) in methanol- $d_{4}$. The UV-visible (UV-Vis) spectrum was determined with a Hitachi UV-Vis spectrometer U-3210 (Hitachi, Ltd., Tokyo, Japan).

$P C$

PC was carried out as described by JSFA-VII ${ }^{18)}$. The development solvent for the PC was a mixture of $n$ butanol, 1\% ammonia solution and absolute ethanol (6: $3: 2$ ), and Toyo filter paper No. 50 (Advantic Toyo Co., Tokyo, Japan) was used for the PC.

\section{HPLC}

$\mathrm{B}-1 \mathrm{Al}(0.1 \mathrm{~g})$ was dissolve in $5 \mathrm{~mL}$ of dilute sulfuric acid $(5 \rightarrow 20)$ and then made up to $100 \mathrm{~mL}$ with $0.1 \mathrm{~mol} /$ $\mathrm{L}$ ammonium acetate solution. After removal of any insoluble material by centrifugation, the supernatant was subjected to analytical HPLC. A $20-\mu \mathrm{L}$ aliquot of the sample solution $(1 \mathrm{mg} / \mathrm{mL}$ as $\mathrm{B}-1 \mathrm{Al})$ was directly chromatographed on a Develosil ODS-UG-5 column (4 mm i.d. $\times 250$ mm, Nomura Chemical Co., Aichi, Japan) 
at $40^{\circ} \mathrm{C}$ with photodiode array detection from 200 to $700 \mathrm{~nm}$, and the flow rate was set at $1.0 \mathrm{~mL} / \mathrm{min}$. Solvents $\mathrm{A}, \mathrm{A}^{\prime}$ and $\mathrm{B}$ were methanol, acetonitrile and 0.02 $\mathrm{mol} / \mathrm{L}$ ammonium acetate solution, respectively. The mobile phases used were two isocratic conditions, a methanol-ammoniumacetate solutionsystem (A/B (38: $62)$ ) and an acetonitrile-ammonium acetate solution system (A'/B (21:79)).

\section{Isolation of subsidiary colors}

B-1Al (sample: I-i, $0.5 \mathrm{~g}$ ) was dissolved in $5 \mathrm{~mL}$ of dilute sulfuric acid $(5 \rightarrow 20)$ and then made up to $50 \mathrm{~mL}$ with water. The solution was then loaded onto a polyamide C-200 column (30 g in nylon foil, $25 \mathrm{~mm}$ i.d. $\times 40$ $\mathrm{cm})$. This column was washed with $10 \%$ acetic acid and

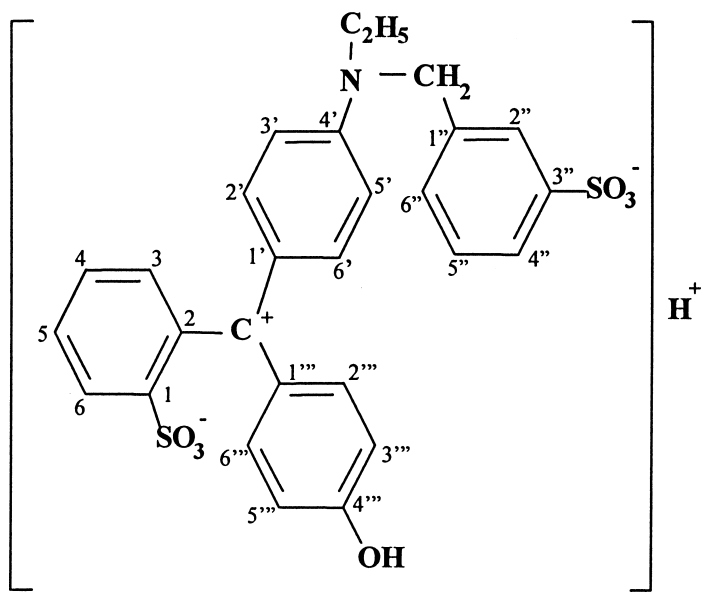

Fig. 2. Chemical structure of Sub-V [free acid of OSBA(HP) $(m$-EBASA)]

Sub-V,2-[[4-[N-ethyl- $N$-(3-sulfophenylmethyl)amino]phenyl][4-hydroxy phenyl]methylio]benzenesulfonic acid. then developed with $800 \mathrm{~mL}$ of a mixture of ethanol and $10 \%$ acetic acid $(7: 3)$. After elution, the violet band in the column was cut out with scissors, and eluted with a mixture of ethanol and $10 \%$ acetic acid $(7: 3)$. The eluate was co-evaporated with ethanol and acetone to give crude Sub-V (20 mg).

Preparative HPLC was performed several times under the above HPLC conditions using a $500-\mu \mathrm{L}$ of injection volume, with a methanol-ammonium acetate solution system as the mobile phase to afford Sub-V $(5 \mathrm{mg})$. To obtain other subsidiary colors, preparative HPLC of the sample I-i was also performed under the conditions described by Matsufuji et al. ${ }^{15)}$. The fractions at the $R t$ of each color were collected and concentrated to give Sub-A $\sim$ E and Sub-M.

\section{Ion chromatography}

Ion chromatography (IC) was used to identify the counter ions of Sub-V. Sodium chloride and ammonium chloride used as standards were separately dissolved in water. The cationic ions in each $5-\mu \mathrm{L}$ aliquot of the solutions were chromatographed on an IonPac CG12A guard column (4 mm i.d. $\times 50 \mathrm{~mm}$, Dionex) and an IonPac CS12A analytical column $(4 \mathrm{~mm}$ i.d. $\times 250 \mathrm{~mm}$, Dionex), with $20 \mathrm{mmol} / \mathrm{L}$ methanesulfonic acid at flow rate of $1.0 \mathrm{~mL} / \mathrm{min}$ at $35^{\circ} \mathrm{C}$, and were detected by conductivity.

\section{Quantification of $S u b-V$ and $m, m-B-1$ by HPLC}

The analytical HPLC was performed with the methanol-ammonium acetate solution system under the conditions described above. Five-point calibration curves were linear from 0.1 to $15 \mathrm{mg} / \mathrm{mL}$ for Sub-V (at 580 $\mathrm{nm}$ ), and from 0.1 to $100 \mathrm{mg} / \mathrm{mL}$ for $m, m$-B-1 (at 630 $\mathrm{nm})$.

Table 1. ${ }^{1} \mathrm{H}-\mathrm{NMR}$ Data ( $\delta$ Value, $600 \mathrm{MHz} / \mathrm{TMS}$ ) for Sub-V in MeOH- $d_{4}{ }^{\mathrm{a})}$

\begin{tabular}{|c|c|c|c|}
\hline \multirow{2}{*}{ Position } & \multirow{2}{*}{ Sub-V } & \multicolumn{2}{|c|}{ Reported data } \\
\hline & & Sub-M ${ }^{b)}$ & Sub-E $E^{c)}$ \\
\hline 3 & $7.09(\mathrm{dd}, J=1.1,8.0)$ & $7.09(\mathrm{dd}, J=1.2,8.1)$ & $7.09(\mathrm{dd}, J=1.1,7.7)$ \\
\hline 4 & $7.55(\mathrm{td}, J=1.1,8.0)$ & $7.52(\mathrm{td}, J=1.2,8.1)$ & $7.55(\mathrm{td}, J=1.1,7.7)$ \\
\hline 5 & $7.63(\mathrm{td}, J=1.1,8.0)$ & $7.58(\mathrm{td}, J=1.2,8.1)$ & $7.63(\mathrm{td}, J=1.1,7.7)$ \\
\hline 6 & $8.12(\mathrm{dd}, J=1.1,8.0)$ & $8.10(\mathrm{dd}, J=1.2,8.1)$ & $8.12(\mathrm{dd}, J=1.1,7.7)$ \\
\hline $2^{\prime}, 6^{\prime}$ & $7.38(\mathrm{~d}, J=9.0)$ & $7.32(\mathrm{~d}, J=8.1)$ & $7.40(\mathrm{~d}, J=7.8)$ \\
\hline $3^{\prime}, 5^{\prime}$ & $6.79(\mathrm{~d}, J=9.0)$ & $6.89(\mathrm{~d}, J=8.1)$ & $6.78(\mathrm{~d}, J=9.0)$ \\
\hline $2^{\prime \prime}$ & $7.74(\mathrm{~s})$ & $7.75(\mathrm{~s})$ & $7.74(\mathrm{~s})$ \\
\hline $4^{\prime \prime}$ & $7.77(\mathrm{~d}, J=7.7)$ & $7.74(\mathrm{~d}, J=7.6)$ & $7.75(\mathrm{~d}, J=7.7)$ \\
\hline $5^{\prime \prime}$ & $7.44(\mathrm{t}, J=7.7)$ & $7.40(\mathrm{t}, J=7.6)$ & $7.42(\mathrm{t}, J=7.7)$ \\
\hline $6^{\prime \prime}$ & $7.34(\mathrm{~d}, J=7.7)$ & $7.32(\mathrm{~d}, J=7.6)$ & $7.32(\mathrm{~d}, J=7.7)$ \\
\hline $2^{\prime \prime \prime}, 6^{\prime \prime \prime}$ & $7.50(\mathrm{~d}, J=8.8)$ & $7.39(\mathrm{~d}, J=8.1)$ & $7.37(\mathrm{~d}, J=7.8)$ \\
\hline $3^{\prime \prime \prime}, 5^{\prime \prime \prime}$ & $7.09(\mathrm{~d}, J=8.8)$ & $6.53(\mathrm{~d}, J=8.1)$ & $6.94(\mathrm{~d}, J=9.0)$ \\
\hline $\mathrm{N}-\mathrm{CH}_{2}-\mathrm{CH}_{3}$ & $1.34(\mathrm{t}, J=7.3)$ & $1.32(\mathrm{t}, J=6.6)$ & $1.31(\mathrm{t}, J=7.2)$ \\
\hline $\mathrm{N}-\underline{C H}_{2}-\mathrm{CH}_{3}$ & $3.85(\mathrm{q}, J=7.3)$ & $3.65(\mathrm{q}, J=6.6)$ & $3.74(\mathrm{q}, J=7.2)$ \\
\hline $\mathrm{N}-\mathrm{CH}_{2}-\mathrm{Ar}$ & $5.03(\mathrm{~s})$ & $4.87(\mathrm{~s})$ & $4.90(\mathrm{~s})$ \\
\hline $\mathrm{N}^{\prime}-\overline{\mathrm{CH}}_{2}^{\prime}{ }_{2}-\underline{\mathrm{CH}}_{3}^{\prime}$ & & & $1.29(\mathrm{t}, J=7.2)$ \\
\hline $\mathrm{N}-\underline{\mathrm{CH}}_{2}{ }_{2}-\mathrm{CH}^{\prime}{ }_{3}$ & & & $3.44(\mathrm{q}, J=7.2)$ \\
\hline
\end{tabular}

a) Multiplicities and coupling constants ( $\delta$ in ppm from TMS) are given in parentheses.

b) Kusaka et al. ${ }^{16)}$

c) Matsufuji et al. ${ }^{15)}$ 


\section{Results and Discussion}

\section{HPLC and structural determination of Sub-V}

The violet sub-spot in one sample (I-i: the product (i) produced by manufacturer "I") of B-1Als, which was rejected in fiscal year 1999, was detected at a slightly higher $R f$ value than the main spot by $\mathrm{PC}^{20)}$. The HPLC with a diode array detector was performed under the HPLC conditions of Matsufuji et al. ${ }^{15)}$. The chromatogram of sample I-i at $625 \mathrm{~nm}$ had five subsidiary colors corresponding to Sub-A $\sim \mathrm{E}^{20)}$ and an additional subsidiary color named Sub-V. The Sub-V peak at Rt 37.6 min was seen at $580 \mathrm{~nm}$. Kusaka et al. obtained a small amount of a magenta color, Sub-M, with an absorption maximum at $585 \mathrm{~nm}$ from a commercial B-1 product ${ }^{16)}$. The $R t$ was similar to that of Sub- ${ }^{20)}$. The absorption maximum of Sub- $\mathrm{V}$ was at $584.0 \mathrm{~nm}$; this was compatible with that of Sub-M. These findings suggested that the structure of Sub-V might be analogous to that of Sub-M.

In the FAB-MS spectra, one quasi-molecular ion peak of Sub-V was obtained at $m / z 550[\mathrm{M}-\mathrm{H}]^{-}$, though Kusaka et al. ${ }^{16)}$ reported two quasi-molecular ion peaks of Sub-M at $m / z 550[\mathrm{M}-2 \mathrm{Na}+\mathrm{H}]^{-}$and $m / z 572[\mathrm{M}-$ $\mathrm{Na}]^{-}$that have the formulas $\mathrm{C}_{28} \mathrm{H}_{24} \mathrm{~N}_{1} \mathrm{O}_{7} \mathrm{~S}_{2}$ and $\mathrm{C}_{28} \mathrm{H}_{23} \mathrm{~N}_{1}$ $\mathrm{Na}_{1} \mathrm{O}_{7} \mathrm{~S}_{2}$, respectively. The ESI-MS spectrum of Sub-V had three quasi-molecular ion peaks at $m / z 274[\mathrm{M}-$ $2 \mathrm{H}]^{2-} / 2, m / z 550[\mathrm{M}-\mathrm{H}]^{-}$and $m / z 572[\mathrm{M}-2 \mathrm{H}+\mathrm{Na}]^{-}$. Of them, the peak at $m / z 550$ which corresponds to $\mathrm{C}_{28} \mathrm{H}_{24} \mathrm{~N}_{1} \mathrm{O}_{7} \mathrm{~S}_{2}$ characterizes the spectrum of Sub-V, compared with that of Sub-M. Namely, Kusaka et al. ${ }^{16)}$ reported only two quasi-molecular ion peaks at $\mathrm{m} / z 274$ and $m / z 572$ in the Sub-M spectrum. These data suggested that a univalent anionic form of Sub-V did not have the OCD moiety with a sodiumsulfonato group, but had the center cation with a sulfonato group. Ion chromatographic analysis revealed that Sub-V did not contain enough sodium as counter cation. These data indicated that Sub-V took acidic form. Therefore, its molecular formula is considered to be as $\mathrm{C}_{28} \mathrm{H}_{25} \mathrm{~N}_{1} \mathrm{O}_{7} \mathrm{~S}_{2}$.

Based on ${ }^{1} \mathrm{H}^{-1} \mathrm{H}$-correlation spectroscopy (COSY), heteronuclear multiple quantum coherence (HMQC), and heteronuclear multiple bond connectivity (HMBC) studies, the ${ }^{1} \mathrm{H}$ - and ${ }^{13} \mathrm{C}-\mathrm{NMR}$ assignments for $\mathrm{Sub}-\mathrm{V}$ with the quoted data for Sub-M and Sub-E are summarized in Tables 1 and 2 . The ${ }^{1} \mathrm{H}$ - and ${ }^{13} \mathrm{C}$-NMR spectra of Sub-V were comparable with those of Sub-M and Sub-E, as shown in Tables 1 and 2, suggesting that it has a structure composed of a 4-[N-ethyl- $N$-(3-sulfophenylmethyl)amino]phenyl group and a 2 -substituted benze-

Table 2. ${ }^{13} \mathrm{C}-\mathrm{NMR}$ Chemical Shift Values $(\delta$ Value, 150 $\mathrm{MHz} / \mathrm{TMS}$ ) of Sub-V in $\mathrm{MeOH}-d_{4}$

\begin{tabular}{|c|c|c|c|}
\hline \multirow{2}{*}{ Position } & \multirow{2}{*}{ Sub-V } & \multicolumn{2}{|c|}{ Reported data } \\
\hline & & Sub-Ma) & Sub-E $E^{b)}$ \\
\hline 1 & 146.1 & 145.7 & 146.5 \\
\hline 2 & 137.5 & 138.9 & 138.5 \\
\hline 3 & 132.6 & 132.6 & 132.8 \\
\hline 4 & 130.5 & 130.7 & 130.7 \\
\hline 5 & 130.8 & 130.5 & 131.2 \\
\hline 6 & 129.4 & 129.3 & 129.4 \\
\hline $1^{\prime}$ & 130.4 & 129.0 & 129.5 \\
\hline $2^{\prime}, 6^{\prime}$ & 140.6 & 139.6 & 141.3 \\
\hline $3^{\prime}, 5^{\prime}$ & 119.3 & 114.0 & 114.3 \\
\hline $4^{\prime}$ & 158.0 & 157.7 & 156.8 \\
\hline $1^{\prime \prime}$ & 138.4 & 139.2 & 138.6 \\
\hline $2^{\prime \prime}$ & 125.4 & 125.3 & 125.3 \\
\hline $3^{\prime \prime}$ & 147.4 & 147.0 & 147.2 \\
\hline $4^{\prime \prime}$ & 126.6 & 126.2 & 126.3 \\
\hline $5^{\prime \prime}$ & 130.2 & 129.9 & 130.0 \\
\hline $6^{\prime \prime}$ & 129.7 & 129.6 & 129.5 \\
\hline $1^{\prime \prime \prime}$ & 127.8 & 129.8 & 128.9 \\
\hline $2^{\prime \prime \prime}, 6^{\prime \prime \prime}$ & 143.4 & 142.2 & 141.3 \\
\hline $3^{\prime \prime \prime}, 5^{\prime \prime \prime}$ & 116.3 & 123.7 & 114.3 \\
\hline $4^{\prime \prime \prime}$ & $162.0^{\mathrm{c})}$ & Not observed & 160.0 \\
\hline $\mathrm{N}-\mathrm{CH}_{2}-\underline{\mathrm{C}} \mathrm{H}_{3}$ & 13.0 & 13.5 & 12.7 \\
\hline $\mathrm{N}-\mathrm{CH}_{2}-\mathrm{CH}_{3}$ & 47.8 & 47.8 & 47.5 \\
\hline $\mathrm{N}-\underline{\mathrm{CH}}_{2}-\mathrm{Ar}$ & 55.3 & 54.9 & 54.7 \\
\hline $\mathrm{N}^{\prime}-\mathrm{CH}_{2}^{\prime}-\underline{\mathrm{CH}}_{3}^{\prime}$ & & & 14.3 \\
\hline $\mathrm{N}^{\prime}-\underline{\mathrm{CH}^{\prime}}{ }_{2}-\mathrm{CH}_{3}$ & & & 39.3 \\
\hline $\mathrm{C}^{+}$ & 176.0 & $172.0^{\mathrm{c})}$ & 178.2 \\
\hline
\end{tabular}

Table 3. Contents of Sub-V in Food Blue No. 1 Aluminum Lakes (B-1Als)

\begin{tabular}{|c|c|c|c|c|c|}
\hline \multirow{2}{*}{ Sample } & \multicolumn{2}{|c|}{$\begin{array}{c}\text { Contents of Sub-V and } m, m-\mathrm{B}-1 \text { in } \\
\text { test solutions }{ }^{\mathrm{a})}\end{array}$} & \multirow{2}{*}{$\begin{array}{l}\text { Contents of B-1 in } \\
\qquad \text { B-1 Als }{ }^{\text {b) }} \\
(\%)\end{array}$} & \multirow{2}{*}{$\begin{array}{l}\text { Relative contents of } \\
\text { Sub-V to } m, m-B-1 \\
(\%)\end{array}$} & \multirow{2}{*}{$\begin{array}{c}\text { Contents of Sub-V } \\
\text { in B-1 } \\
(\%)\end{array}$} \\
\hline & $\begin{array}{c}\mathrm{Sub}-\mathrm{V} \\
(\mu \mathrm{g} / \mathrm{mL})\end{array}$ & $\begin{array}{l}m, m-\mathrm{B}-1 \\
(\mu \mathrm{g} / \mathrm{mL})\end{array}$ & & & \\
\hline $\mathrm{I}-\mathrm{i}$ & 30.0 & 76.1 & 15.4 & 39.5 & 19.5 \\
\hline ii & 0.8 & 69.9 & 12.0 & 1.1 & 0.7 \\
\hline II-i & 0.8 & 75.8 & 12.5 & 1.1 & 0.6 \\
\hline ii & 2.3 & 78.8 & 11.3 & 2.9 & 2.0 \\
\hline iii & 2.0 & 78.0 & 13.4 & 2.5 & 1.5 \\
\hline iv & 1.8 & 77.8 & 13.3 & 2.3 & 1.3 \\
\hline $\mathrm{V}$ & 2.1 & 82.1 & 14.0 & 2.6 & 1.5 \\
\hline III-i & 2.8 & 77.0 & 11.2 & 3.6 & 2.5 \\
\hline
\end{tabular}

a) Data were obtained by HPLC using a mixture of methanol-ammonium acetate solution as the mobile phase. See footnotes of Fig. 3-1 for HPLC conditions.

b) Contents of B-1 in B-1Als were determined by the titanium trichloride mehtod. 


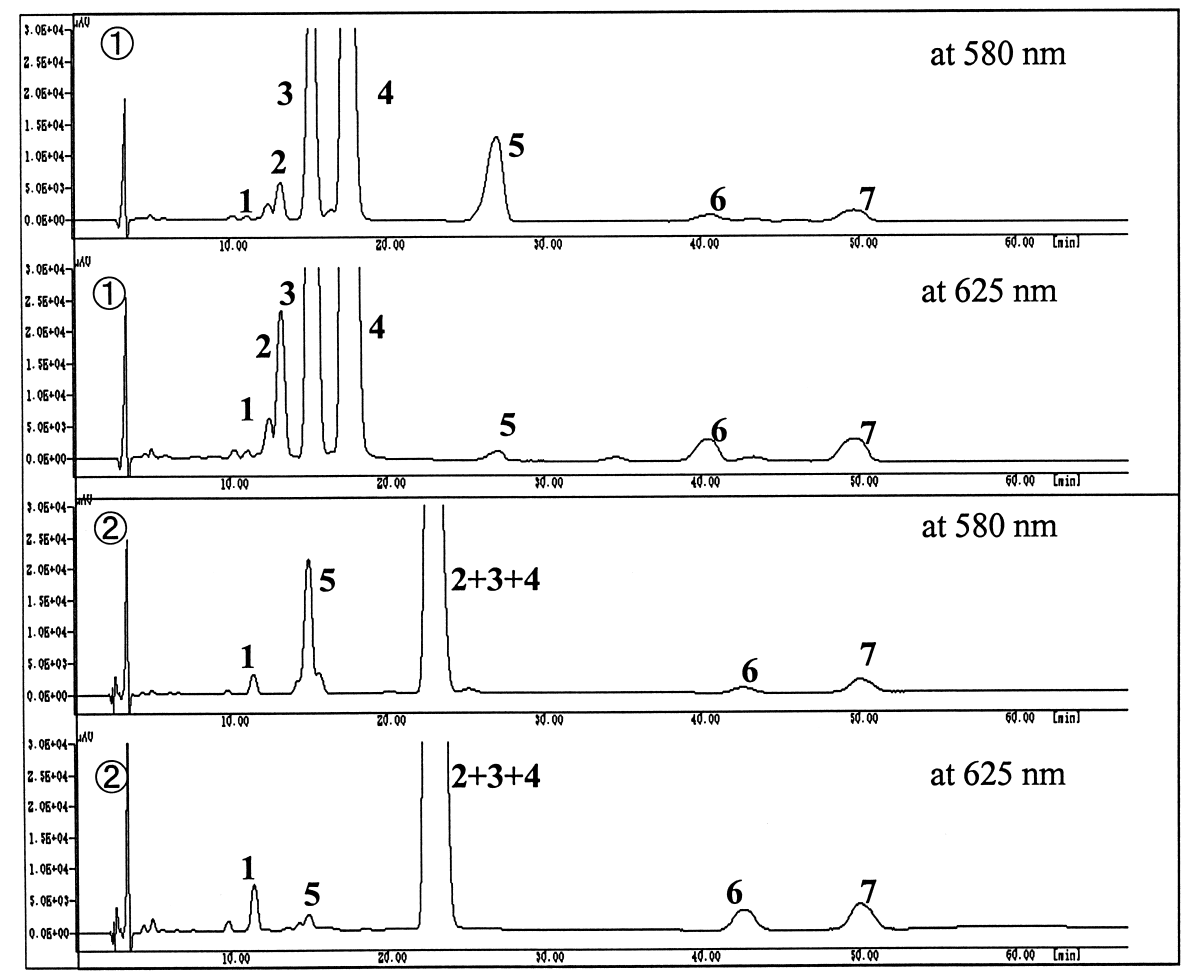

Retention time (min)

Fig. 3. High performance liquid chromatograms of Food Blue No. 1 aluminum lake (sample I-i) with different mobile phases

$m, m$-B-1 and its subsidiary colors: 1, Sub-A; 2, Sub-B; 3, Sub-C; 4, m,m-B-1; 5, Sub-V; 6, Sub-D; 7, Sub-E

Sub-A $\sim$ D were isolated from sample I-i using Matsufuji's HPLC conditions ${ }^{15)}$. The presence of Sub-F was not recognized. The structure of Sub-A and B are not identified.

HPLC conditions

Column, Develosil ODS UG5 (4.6 mm i.d. $\times 250 \mathrm{~mm}$ ); column temp., $40^{\circ} \mathrm{C}$; detected wavelengths, $580 \mathrm{~nm}$ and $625 \mathrm{~nm}$; flow rate, $1.0 \mathrm{~mL} / \mathrm{min}$; sample size, $20 \mu \mathrm{L}$

Solvents $\mathrm{A}, \mathrm{A}^{\prime}$ and $\mathrm{B}$ are methanol, acetonitrile and $0.02 \mathrm{~mol} / \mathrm{L}$ ammonium acetate solution, respectively.

Two mobile phases: methanol-ammonium acetate solution system is a mixture of solvents A and B (1) A/B (38: $62)$ ), and the other is an acetonitrile-ammonium acetate solution system (2) $\mathrm{A}^{\prime} / \mathrm{B}(21: 79)$ ).

nesulfonic acid group. The ${ }^{1} \mathrm{H}$ - and ${ }^{13} \mathrm{C}-\mathrm{NMR}$ spectra of Sub-V and Sub-E were analogous except for the lack of an $N$-ethyl group $[\delta 1.29(3 \mathrm{H}, \mathrm{t}, J=7.2 \mathrm{~Hz}), \delta 3.44(2 \mathrm{H}$, q, $J=7.2 \mathrm{~Hz})]$. The main difference in the ${ }^{1} \mathrm{H}-\mathrm{NMR}$ spectra between Sub-V and Sub-M was a significant downfield shift for $\mathrm{H}-3^{\prime \prime \prime}$ and $\mathrm{H}-5^{\prime \prime \prime}(\delta 7.09 \leftarrow \delta 6.53)$. Furthermore, the ${ }^{13} \mathrm{C}-\mathrm{NMR}$ spectrum of Sub-V also showed distinctive upfield shifts for $\mathrm{C}-3^{\prime \prime \prime}$ and $\mathrm{C}-5^{\prime \prime \prime}[\delta 116.3 \leftarrow \delta$ 123.7], analogous to those for Sub-E. Considering these chemical shifts and coupling patterns, it was suggested that Sub-V has a hydroxybenzene moiety rather than the OCD moiety of Sub-M. This conclusion is consistent with the estimated formula. Therefore, the structure of Sub-V was concluded to be 2-[4-[ $N$-ethyl- $N$-(3-sulfophenylmethyl)amino]phenyl][4-hydroxy phenyl]methylio]benzenesulfonic acid (Fig. 2). Considering the structures of Sub-M and Sub-V, their origin should be the same, and Sub-M might be converted to Sub-V during the preparation of B-1Al.
Quantification of Sub- $V$ and $m, m-B-1$ in tested $B-1 A l$ by HPLC

Matsufuji et al. used a methanol-ammonium carbonate solution system as the mobile phase ${ }^{15)}$. On the other hand, the HPLC conditions for azo food colors as described in JSFA-VII ${ }^{18}$ ) have used a methanol-ammonium acetate solution system or an acetonitrile-ammonium acetate solution system as the mobile phase. If HPLC of food azo colors and B-1 can be simultaneously performed, it wolud save time in routine analyses. Therefore, we examined the HPLC using the same mobile phases as described in JSFA-VII.

With the methanol-ammonium acetate solution system (see Fig. 3-1), m,m-B-1 and subsidiary colors peaks were eluted with Rts similar to those cited by Matsufuji et al. ${ }^{15)}$. The diode array spectrum of Sub-V had an absorption maximum at $574 \mathrm{~nm}$ which was slightly shorter than that of Sub-M at $580 \mathrm{~nm}$. Sub-B, Sub-C and Sub-D showed the same absorption maximum at $634 \mathrm{~nm}$ as that of $m, m$-B-1. The maxima of Sub-A and E were at $622 \mathrm{~nm}$ and $616 \mathrm{~nm}$, respectively, and these wavelengths are longer than the correspond- 
ing ones reported by Matsufuji et $a l .{ }^{15)}$.

In an acetonitrile-ammonium acetate solution system (see Fig. 3-(2)), the Sub-V peak was eluted before the $m$, $m$-B-1 peak. Moreover, Sub-B and C, and the $m, m$-B-1 peaks were eluted at the same $R t$. Sub-C and Sub-D are the $m, p$ - and $o, m$-isomers of $m, m$-B-1, respectively.

The contents of Sub-V in 8 samples of B-1Als in an official inspection were determined using HPLC with the methanol-ammonium acetate solution system; the results are shown in Table 3. The content of Sub-V in the rejected sample was remarkably high. However, those in other samples were in the range of $1.1-3.6 \%$ and were similar to those of Sub-M (0.1-0.8\%) in commercial B-1 products ${ }^{16)}$.

The manufacturer "I" was instructed to use B-1 certified according to the requirement of JSFA-VII for the preparation of B-1Al. Subsequently, the content of Sub-V in sample I-ii prepared by the same manufacturer was reduced to a very low level.

\section{Acknowledgements}

We are grateful to Dr. Yukihiro Goda, NIHS, for helpful suggestions on the interpretation of FAB-MS data.

\section{References}

1) Takeda, Y., Goda, Y., Noguchi, H., Yamada, T., Yoshihira, K., Takeda, M., Spectroscopic characterization of SCNTR: a subsidiary dye of Allura Red AC (FD \& C Red No. 40). Food Additives and Contaminants, 11, 97-104 (1994).

2) Takeda, Y., Kamikura, M., Shibata, T., Ito, Y., Yoshihira, K., Determination of subsidiary colors in Food Red No. 40 by high performance liquid chromatography. Shokuhin Eiseigaku Zasshi (J. Food Hyg. Soc. Japan), 34, 39-44 (1993).

3) Ishimitsu, S., Mishima, I., Tsuji, S., Shibata, T., Determination and survey of starting materials, intermediates, and subsidiary colors in food color of azo dye by high performance liquid chromatography. Kokuritsu Iyakuhin Shokuhin Eisei Kenkyusho Ho (Bull. Natl. Inst. Health Sci.), 115, 175-180 (1997).

4) Tsuji, S., Amakura, Y., Okada, M., Tonogai, Y., Modification of HPLC conditions for the determinations of raw materials, intermediates and subsidiary colors in 5 kinds of food azo colors. Shokuhin Eiseigaku Zasshi (J. Food Hyg. Soc. Japan), 42, 114-121 (2001).

5) Yamada, M., Kato, Y., Nakamura, M., Yamada, T., Maitani, T., Goda, Y., Structural determination of unknown subsidiary colors in commercial Food Red Nos. 2 and 102. Chem. Pharm. Bull., 46, 494-499 (1998).

6) Uematsu, Y., Hirokado, M., Nakajima, K., Takahashi, I., Matsui, K., Kazama, M., High performance liquid chromatographic determination of impurities in Amaranth, New Coccine and Sunset Yellow FCF. Tokyo Toritsu Eisei Kenkyusho Kenkyu Nenpo (Ann. Rep. Tokyo Metr. Res. Lab. P. H.), 38, 245-252 (1987).

7) Yamada, M., Kato, Y., Nakamura, M., Yamada, T., Maitani, T., Goda, Y., Survey of raw materials and subsidiary colors in commercial Food Red Nos. 2 and 102. Nippon Shokuhin Kagaku Gakkaishi (Jpn. J. Food
Chem.), 4, 107-113 (1997).

8) Uematsu, Y., Hirokado, M., Nakajima, K., Takahashi, I., Matsui, K., Kazama, M., New Coccine and Sunset Yellow FCF. II. Determination of subsidiary colors. Tokyo Toritsu Eisei Kenkyusho Kenkyu Nenpo (Ann. Rep. Tokyo Metr. Res. Lab. P. H.), 39, 151-155 (1988).

9) Yamada, M., Kato, Y., Nakamura, M., Ishimitsu, S., Shibata, T., Ito, Y., Determination and survey of starting materials and subsidiary colors in new coccine by high performance liquid chromatography, Shokuhin Eiseigaku Zasshi (J. Food Hyg. Soc. Japan), 36, 417-422 (1995).

10) Kamikura, M., Yoshihira, K., Goda, Y., Structural determination of subsidiary colors in Food Red No. 104 and their contents in commercial products. Shokuhin Eiseigaku Zasshi (J. Food Hyg. Soc. Japan), 40, 455-459 (1999).

11) Yamada, M., Nakamura, M., Yamada, T., Maitani, T., Goda, Y., Structural determination of unknown subsidiary colors in Food Yellow No. 5 (Sunset Yellow FCF). Chem. Pharm. Bull., 44, 1,624-1,627 (1996).

12) Yamada, M., Inoue, T., Kato, Y., Nakamura, M., Shibata, T., Kimura, M., Tsuji, S., Ito, Y., Determination and survey of starting materials, intermediates, and subsidiary colors in sunset yellow FCF. Shokuhin Eiseigaku Zasshi (J. Food Hyg. Soc. Japan), 34, 239-247 (1993).

13) Tsuji, S., Matsumura, I., Nakamura, Y., Tonogai, Y., Studies on separation and determination of subsidiary colors, raw materials and intermediates in Food Yellow No. 5 (sunset yellow FCF). Shokuhin Eiseigaku Zasshi (J. Food Hyg. Soc. Japan), 41, 357-363 (2000).

14) Kamikura, M., Structures of subsidiary colors in Food Blue No. 1 and their separation and determination by high performance liquid chromatography. Shokuhin Eiseigaku Zasshi (J. Food Hyg. Soc. Japan), 27, 27-36 (1986).

15) Matsufuji, H., Kusaka, T., Tsukuda, M., Chino, M., Kato, Y., Nakamura, M., Goda, Y., Toyoda, M., Takeda, M., Structural determination of subsidiary colors in commercial Food Blue No. 1 (brilliant blue FCF) product. Shokuhin Eiseigaku Zasshi (J. Food Hyg. Soc. Japan), 39, 7-12 (1998).

16) Kusaka, T., Matsufuji, H., Chino, M., Kato, Y., Nakamura, Y., Goda, Y., Toyoda, M., Takeda, M., Isolation, identification and determination of a magenta subsidiary color in Food Blue No. 1 (Brilliant Blue FCF). Food Additives and Contaminants, 16, 501-507 (1999).

17) Kamikura, M., Structures of subsidiary colors in Food Green No. 3 and their separation and determination by high performance liquid chromatography. Shokuhin Eiseigaku Zasshi (J. Food Hyg. Soc. Japan), 27, 398-407 (1986).

18) Japan's Specifications and Standards for Food Additives, 7th Ed., Japanese Ed., Ministry of Health and Welfare, Japan, 1999, pp. 25-34, 294-295, 298-302, 305306, 308-309.

19) Stein, C., Subsidiary colors in FD \& C Blue No. 1. J. Assoc. Off. Anal. Chem., 52, 34-40 (1969).

20) Tsuji, S., Amakura, Y., Okada, M., Tonogai, Y., Studies on rejected Food Blue No. 1 (Brilliant Blue FCF) aluminum lake. Kokuritsu Iyakuhinn Shokuhin Eisei Kenkyusho Ho (Bull. Natl. Inst. Health Sci.), 118, 131-138 (2000). 